\title{
Comparative evaluation of remaining dentin thickness with three different rotary Ni-Ti File systems: an in vitro CBCT study
}

\author{
Durga Bhavani Panithini ${ }^{1,}$, Sita Rama Kumar M², Girija S Sajjan³, Madhu Varma K³, Kalyan Satish R³, Manishaa B ${ }^{1}$ \\ ${ }^{1}$ Postgraduate Student, ${ }^{2}$ Reader, ${ }^{3}$ Professor, Department of Conservative Dentistry and Endodontics, Vishnu Dental College, Bhimavaram, Andhra Pradesh, \\ India - 534202 .
}

\section{Article History}

Received $4^{\text {th }}$ June 2021

Received revised

$23^{\text {rd }}$ August 2021

Accepted $10^{\text {th }}$ September2021

Available online

$6^{\text {th }}$ February 2022

\section{*Correspondence}

Durga Bhavani Panithini

Postgraduate Student

Department of Conservative Dentistry and Endodontics

Vishnu Dental College

Bhimavaram, Andhra Pradesh

India - 534202

E-mail: durgabhavanipanitini@gmail.com

DoI: $\underline{\text { http://dx.doi.org/10.37983/IJDM.2022.4102 }}$

\begin{abstract}
Background: Endodontic therapy and its success depend on effective cleaning and shaping the root canal without deviating from the original anatomy. Ideally, during root canal preparation, the instruments should always confine to and retain the original shape of the canal to maximize the cleaning effectiveness and minimize unnecessary weakening of tooth structure to achieve the optimal result. The remaining dentin thickness in endodontically treated teeth is a significant factor, which is responsible for its longevity.

Aim: This study aimed to evaluate the remaining dentin thickness after instrumentation with ProTaper Next (PTN), TruNatomy (TN), and Neohybrid (NH) file systems using cone-beam computed tomography.

Materials and methods: Thirty extracted single-rooted mandibular premolars were decoronated and divided into three experimental groups with ten in each. Groups I, II, and III were assigned to the file systems ProTaper Next (PTN), TruNatomy (TN), and Neohybrid (NH), respectively. Cone-beam computed tomographic pre-scans were taken, followed by the biomechanical preparation with the respective file systems. Post CBCT scans were taken and compared with pre-scans for remaining dentin thickness. The data obtained were statistically analyzed.

Results: Among the three file systems, TruNatomy rotary files resulted in significantly less dentin removal $(p<0.05)$. The majority of the intergroup comparisons showed significant differences in remaining dentin thickness after biomechanical preparation at 3,6, and $9 \mathrm{~mm}$.

Conclusion: TruNatomy (TN) exhibited the maximum remaining dentin thickness followed by Neohybrid (NH) and comparatively minimum with ProTaper Next (PTN) file systems.

Keywords: Cone-beam computed tomography (CBCT), Neohybrid, ProTaper Next, Remaining Dentin Thickness, TruNatomy.
\end{abstract}

\section{Introduction}

The success of root canal treatment varies on effective cleaning and shaping of the root canal system without deviating from the original anatomy [1]. Cleaning and shaping techniques, regardless of instrumentation approach, always result in dentin removal from canal walls. Excessive canal flaring can diminish dentin thickness, resulting in less residual dentin thickness and an increased risk of vertical root fractures [2]. NiTi rotary instruments made root canal preparation easier and faster than manual instrumentation, resulting in reliable and predictable root canal shaping. These instruments can improve both the morphological characteristics and safety of canal shaping because of the alloy's unique properties [3]. The ProTaper Next (PTN) (Dentsply Sirona Endodontics, Ballaigues, Switzerland) is an innovative NiTi file system made from M-Wire technology. It has a rectangular cross-section and an offset mass of rotation with a variable taper. Its offcentered design gives the file snake-like "swaggering effects" that decrease the screw effect and the taper lock minimizing the contact between a file and dentin [4]. TruNatomy (TN) and Neohybrid (NH) file systems that were introduced recently are made up of special $\mathrm{Ni}-\mathrm{Ti}$ alloys and are subjected to various thermal treatments processes. TruNatomy (TN) (Dentsply Sirona, Ballaigues, Switzerland) file system is characterized by different geometries, sizes, memory, and specific metallurgical treatment. It is designed from a $0.8 \mathrm{~mm}$ NiTi wire that is heated by a special treatment, resulting in super-elastic properties and less memory. Also, this wire has been claimed to provide minimally invasive instrumentation because of its geometry, regressive tapers, and slim design $[5,6]$. Neohybrid $(\mathrm{NH})$ (Orikam Healthcare India Private Limited) files are made of CTA (controlled thermal activation) wire with an off-centered rectangular crosssection that improves flexibility. Further, its swaggering 
movement minimizes the engagement between the file and canal dentin, effectively reducing the taper lock and screw-in forces inside the canal [7].

A noninvasive Cone-beam computed tomography (CBCT) is used to evaluate the canal anatomy and compare the canal shape before and after preparation. Using Cone-beam computed tomography (CBCT), proper cross-sections of roots are provided, and 3-dimensional CBCT images are reconstructed simultaneously with more precision than other routine techniques [8]. Limited research is available on the comparison of the efficiency of TruNatomy (TN) and Neohybrid (NH) files in maintaining the remaining dentin thickness. Considering the factors mentioned above, Remaining dentin thickness after instrumentation with ProTaper Next (PTN), TruNatomy (TN), and Neohybrid (NH) Ni-Ti rotary file systems using CBCT were evaluated in this study.

\section{Materials and Methods}

\subsection{Selection and specimen preparation}

A total of thirty freshly extracted human single-rooted mandibular premolar teeth for orthodontic treatment purposes were gathered for the study. The calculation of sample size was based on a previous study using $G$ power software at $80 \%$ confidence and a p-value set at less than 0.05 [1]. Teeth with any previous endodontic treatment, fractures, pathological root resorptions, calcifications, and immature teeth were excluded from the study. The presence of a single root and canal without any curvatures in each tooth was confirmed on radiovisiography (Digora, The Dental Imaging Company Ltd). The samples were standardized to a length of $16 \mathrm{~mm}$ by decoronation using a double-faced diamond disc (KG Sorensen, Barueri, SP, Brazil). The root canal length was measured by the penetration of a size $10 \mathrm{~K}$ file (Mani, Japan) until it reached the apical foramen and then subtracting $0.5 \mathrm{~mm}$. Teeth were arbitrarily divided into three groups $(n=10)$ and were embedded in the putty blocks to obtain a constant position.

\subsection{Initial scanning}

The template was horizontally fitted to chin support with its occlusal plane parallel to the plate. A pre-CBCT (CS 9000 3D, Rainbow CT, South Korea) scan was done for all teeth before instrumentation with the exposure period of 3.0 seconds at $75 \mathrm{kV}$ and $2.0 \mathrm{~mA}$. The scanned images were stored in the computer's hard disk for further comparison between pre and post instrumentation data using DICOM software.

\subsection{Root canal preparation}

After initial scans, root canals were instrumented as follows. Group 1: Canals were shaped using ProTaper Next (PTN) rotary files (X1; 20/0.04 taper and X2; 25/0.06 taper) Group 2: Canals were shaped using TruNatomy (TN) rotary file (25/0.04 taper) Group 3: Canals were shaped using Neohybrid $(\mathrm{NH})$ rotary file
(25/0.04 taper) till the working length with EConnect S (Eighteeth, China) Endo motor. All the instruments and techniques of usage were according to the manufacturing instructions. Biomechanical preparation was done using the respective files, and irrigation was done with $2 \mathrm{ml}$ of $3 \%$ sodium hypochlorite $(\mathrm{NaOCl})$ (Parcan, Septodont Healthcare PVT LTD., India) for $1 \mathrm{~min}$, and recapitulation was done after every instrument. After the instrumentation of the root canal was completed, $2 \mathrm{ml}$ of 17\% ethylenediaminetetraacetic acid (EDTA) (Dent Wash, Prime Dental PVT LTD., India) was applied for $1 \mathrm{~min}$ to remove the smear layer. Then, the canal was flushed again with $2 \mathrm{ml}$ of $3 \% \mathrm{NaOCl}$ and $2 \mathrm{ml}$ of $0.9 \%$ normal saline solution for $1 \mathrm{~min}$ each to remove remnants of EDTA.

\subsection{Final scanning and evaluations}

The teeth were again prepared for post-operative CBCT scanning using the same parameters, and the pre instrumentation data stored were compared with postinstrumentation data using CBCT software (Kodak 9000 DICOM Software CS 9000 3D). Three axial tomograms were selected for each specimen. The first corresponds to the area located at $3 \mathrm{~mm}$ (apical third), the second at 6 $\mathrm{mm}$ (middle third), and the third at $9 \mathrm{~mm}$ (cervical third) from the root apex. The remaining dentin thickness was determined by subtracting the un instrumented canal from the instrumented canal, calculating the shortest distance from the outer wall to the inside canal wall on mesial and distal aspects at the levels of 3,6 , and $9 \mathrm{~mm}$ of pre and post instrumentation [1] (Figure 1-3). Matam et al. used the formula RDT = D1-D2, where D1 is the pre instrumentation dentin thickness and D2 is the post instrumentation dentin thickness $[9,10]$.

\subsection{Statistical analysis}

The data were subjected to statistical analysis using the Statistical Package for the Social Sciences IBM SPSS Statistics version 22.0 software and Oneway Analysis of Variance test for intragroup comparison and Tukey's post hoc test for intergroup examination.

\section{Results}

TruNatomy rotary files significantly resulted in a lesser amount of dentin removal among the three file systems $(p<0.05)$. (Table 1). One-way ANOVA showed no significant difference in the intragroup comparison of group I and group II at 3,6 and $9 \mathrm{~mm}$. In contrast, a significant difference $(\mathrm{p}=0.001)$ is observed in group III at 3,6 and $9 \mathrm{~mm}$ (Table 1).

In post hoc analysis, Group I showed significant differences with Groups II at 3mm, $6 \mathrm{~mm}$, and $9 \mathrm{~mm}$ ( $p=0.003, p=0.001$, and 0.030 , respectively). Also, Group I exhibited a significant difference with Group III at $3 \mathrm{~mm}$ $(p=0.000)$. However, no significant differences were observed between Group II and III at different levels (Table 2). 
Table 1. Intragroup comparison of amount of dentin removal after biomechanical preparation with three different file systems at 3,6 , and $9 \mathrm{~mm}$.

\begin{tabular}{lcccc}
\hline Groups & Levels & Mean & Standard Deviation & $\boldsymbol{p}$-Value \\
\hline \multirow{3}{*}{ Group I (PTN) } & $3 \mathrm{~mm}$ & 0.31 & 0.20 & \multirow{2}{*}{0.683} \\
\cline { 2 - 4 } & $6 \mathrm{~mm}$ & 0.29 & 0.19 & \\
\cline { 2 - 4 } Group II (TN) & $9 \mathrm{~mm}$ & 0.26 & 0.13 \\
\cline { 2 - 4 } & $3 \mathrm{~mm}$ & 0.17 & 0.06 & 0.099 \\
\cline { 2 - 4 } Group III (NH) & $6 \mathrm{~mm}$ & 0.13 & 0.04 & \multirow{2}{*}{0.001} \\
\cline { 2 - 4 } & $9 \mathrm{~mm}$ & 0.17 & 0.06 & \\
\hline
\end{tabular}

Table 2. Inter-group comparison of amount of dentin removal after biomechanical preparation with three different file systems at 3,6 , and $9 \mathrm{~mm}$.

\begin{tabular}{lccccc}
\hline \hline levels & \multicolumn{2}{c}{ Groups } & Mean difference & Standard Error & Significance* \\
\hline \multirow{3}{*}{$3 \mathbf{m m}$} & \multirow{2}{*}{ Group I } & Group II & 0.14 & 0.04 & 0.003 \\
\cline { 2 - 6 } & & Group III & 0.17 & 0.04 & 0.000 \\
\cline { 2 - 6 } & Group II & Group III & 0.03 & 0.04 & 0.750 \\
\hline \multirow{3}{*}{$\mathbf{6 m m}$} & \multirow{2}{*}{ Group I } & Group II & 0.16 & 0.04 & 0.001 \\
\cline { 2 - 6 } & \multirow{2}{*}{ Group II } & Group III & 0.06 & 0.04 & 0.339 \\
\hline \multirow{3}{*}{$\mathbf{9 m m}$} & \multirow{2}{*}{ Group I } & Group III & 0.10 & 0.04 & 0.055 \\
\cline { 2 - 6 } & \multirow{2}{*}{ Group II } & Group II & 0.09 & 0.03 & 0.954 \\
\hline
\end{tabular}

${ }^{*}$ The mean difference is significant at the level of 0.05 .
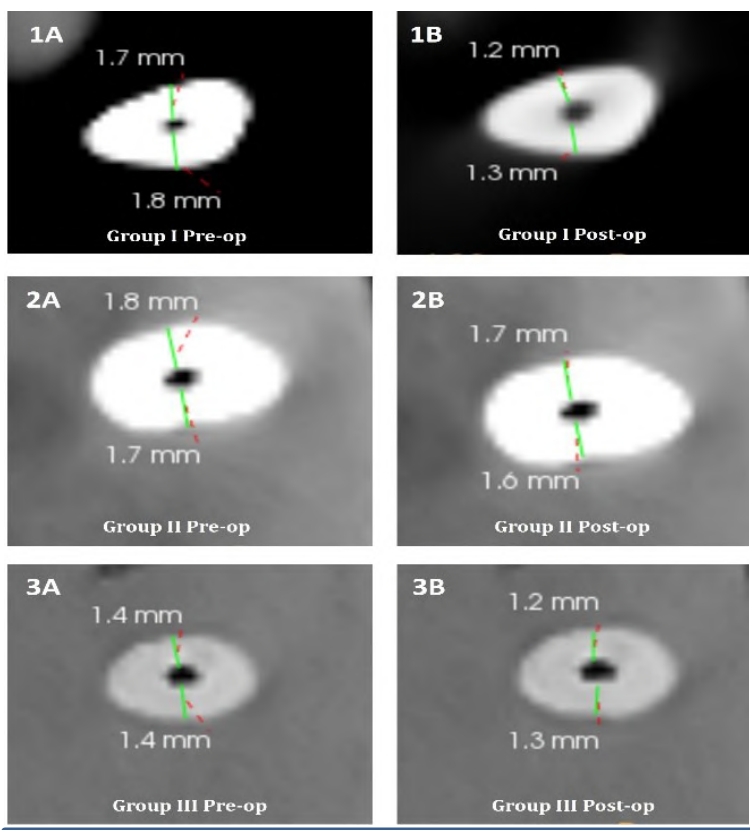

Figure 1-3. A Showing pre-instrumentation images; B. Showing post-instrumentation images of 1. ProTaper Next (PTN), 2. TruNatomy (TN), and 3 .Neohybrid (NH) at the region of $9 \mathrm{~mm}$ from the apex.

\section{Discussion}

An ideally prepared root canal should have a progressively tapering conical shape that preserves the apical foramen and the original canal shape [3]. The thickness of the remaining root dentin following intraradicular procedures may be the most important iatrogenic factor that may lead to compromised fracture resistance of the root $[3,10]$. This study was performed on single-rooted, single canal mandibular premolars to avoid bias [9]. In this study, CBCT was used to evaluate the remaining root dentin thickness. There are several methodologies to evaluate different instrumentation techniques in preparing root canals. But one of the latest innovations in the medical field is the use of CBCT for study purposes and this scientific tool that could develop potential in endodontic research. Moreover, the quality of the three-dimensional images obtained by CBCT scanning is an accurate and efficient method of assessing root canal instrumentation [2,11,12]. The advantages of NiTi instruments in root canal preparation are well documented. However, their cutting ability is a complex interrelationship of multiple parameters such as the cross-sectional design, helical and rake angles, metallurgical properties, and surface treatments of the instrument [13]. 
In the present study, three file systems, namely, ProTaper Next (PTN), TruNatomy (TN), Neohybrid $(\mathrm{NH})$ rotary file systems were used. The results of this study found that the mean value with more amount of remaining dentin thickness after biomechanical preparation at 3,6, and $9 \mathrm{~mm}$ from apical foramen was seen in Group II (TN) followed by Group III (NH) and less in Group I (PTN). The results of this study were similar to the study done by Suhashini Ramanathan et al., who observed that the $\mathrm{M}$ two system removed less amount of dentin and better maintained the original shape of the root canal $(\mathrm{P}<0.05)$ than ProTaper Next (PTN), and Protaper universal systems [14]. It can be mainly attributed to the progressive taper of the ProTaper Next (PTN) files along the cutting surface combined with sharp cutting edges. The results are analyzed both at 3,6 , and $9 \mathrm{~mm}$ from the apex in all the groups to understand the effect of the shape of the instruments, a percentage increase in the taper of the instrument in cleaning and shaping the root canal, and its mechanical properties. It is known that rotary instruments with the same tip size and tapers would cause a similar amount of dentin removal, where the amount of dentin removed would be higher with a larger taper with the same tip size. Similarly, in the present study, ProTaper Next (PTN) files with a larger taper than TruNatomy (TN) and Neohybrid (NH) files removed more amount of dentin [15]. Regressive taper, make the instruments slimmer at the end of the working part than most conical NiTi instruments of comparable ISO size, preventing unnecessary loss of tooth substance in the coronal part [16]. As TruNatomy (TN) files having regressive taper preserved more amount of dentin in the coronal part. It has shown a significant difference in minimum removal of dentin thickness compared to the ProTaper Next (PTN) file system because of its characteristic slim wire design of having a maximum fluted diameter of $0.8 \mathrm{~mm}$. It was stated that the TruNatomy (TN) instruments safeguard the structural dentin and tooth integrity due to their instrument geometry, regressive tapers, and slim design, along with the heat treatment of the NiTi alloy $[6,17]$. Neohybrid $(\mathrm{NH})$ has removed less amount of dentin comparative to ProTaper Next (PTN) file system with a significant difference at $3 \mathrm{~mm}$ from the apex. As given by the manufacturer, its swaggering movement minimizes the engagement between the file and canal dentin, effectively reducing the taper lock and screw-in forces inside the canal, attributing to minimal removal of dentin [7]. The more the dentin is retained, the more the longevity of the teeth. Thus, long-term retention and resistance to fracture of the tooth are directly related to the residual tooth structure.

The present study focused on evaluating the remaining dentin thickness on mandibular premolars. Only singlerooted teeth were evaluated, and in vitro studies do not fully replicate in vivo settings. Therefore, further studies may be focused on evaluating the RDT on molars.

\section{Conclusion}

Within the limitations of this study, it was concluded that maximum remaining dentin thickness was seen with TruNatomy (TN) followed by Neohybrid (NH), and comparatively minimum with ProTaper Next (PTN) file systems.

Conflicts of interest: Authors declared no conflicts of interest.

\section{Financial support: None}

\section{References}

1. Jain A, Asrani H, Singhal AC, Bhatia TK, Sharma V, Jaiswal P. Comparative evaluation of canal transportation, centering ability, and remaining dentin thickness between WaveOne and ProTaper rotary by using cone-beam computed tomography: An in vitro study. J Conserv Dent. 2016;19(5):440. $\quad$ https://doi.org/10.4103/0972$\underline{0707.190024}$

2. Rao MR, Shameem A, Nair R, Ghanta S, Thankachan RP, Issac JK. Comparison of the remaining dentin thickness in the root after hand and four rotary instrumentation techniques: An in vitro study. J Contemp Dent Pract. 2013;14(4):712. $\quad$ https://doi.org/10.5005/jp-journals10024-1389

3. Chaudhary NR, Singh DJ, Somani R, Jaidka S. Comparative evaluation of the efficiency of different file systems in terms of remaining dentin thickness using cone-beam computed tomography: An in vitro study. Contemp clin Dent. 2018;9(3):367.

4. Capar ID, Ertas H, Ok E, Arslan H, Ertas ET. Comparative study of different novel nickel-titanium rotary systems for root canal preparation in severely curved root canals. J Endod. 2014;40(6):852-6. https://doi.org/10.1016/i.joen.2013.10.010

5. Peters OA, Arias A, Choi A. Mechanical properties of a novel nickel-titanium root canal instrument: stationary and dynamic tests. J Endod. 2020;46(7):994-1001. https://doi.org/10.1016/i.joen.2020.03.016

6. Kabil E, Katić M, Anić I, Bago I. Micro-computed Evaluation of Canal Transportation and Centering Ability of 5 Rotary and Reciprocating Systems with Different Metallurgical Properties and Surface Treatments in Curved Root Canals. J Endod. 2021;47(3):477-84 https://doi.org/10.1016/i.joen.2020.11.003

7. Orikamhealthcare Neohybrid brochure. Available at https://orikamhealthcare.com/product/neohybrid/. Accessed Dec 15, 2020.

8. Madani ZS, Haddadi A, Haghanifar S, Bijani A. Cone-beam computed tomography to evaluate apical transportation in root canals prepared by two rotary systems. Iran Endod J. 2014;9(2):109-112.

9. Suneetha MG, Moiz AA, Sharief H, Yedla K, Baig MM, Al Qomsan MA. Residual root dentin thickness for three different rotary systems: A comparative cone-beam computed tomography in vitro study. J Indian Soc Pedod Prev Dent. 2020;38(1):48-55.

https://doi.org/10.4103/JISPPD.JISPPD 19019

10. Yadav SS. Comparative evaluation of remaining dentin thickness post instrumentation with three different single rotary file systems-An in vitro CBCT study. International 
Journal of Medical Science and Diagnosis Research. 2020;4(2): 1-4.

11. Jain A, Gupta AS, Agrawal R. Comparative analysis of canal-centering ratio, apical transportation, and remaining dentin thickness between single-file systems, i.e., OneShape and WaveOne reciprocation: An in vitro study. J Conserv Dent. 2018;21(6):637.

https://doi.org/10.4103/JCD.JCD 101_18

12. Elnaghy AM, Elsaka SE. Evaluation of root canal transportation, centering ratio and remaining dentin thickness associated with ProTaper Next instruments with and without glide path. J Endod. 2014;40(12):2053-6. https://doi.org/10.1016/j.joen.2014.09.001

13. Hashem AA, Ghoneim AG, Lutfy RA, Foda MY, Omar GA. Geometric analysis of root canals prepared by four rotary NiTi shaping systems. J Endod. 2012;38(7):9961000. https://doi.org/10.1016/i.joen.2012.03.018

14. Ramanathan S, Solete P. Cone-beam Computed Tomography Evaluation of Root Canal Preparation using Various Rotary Instruments: An in vitro Study. J Contemp Dent Pract. 2015;16(11):869-72. https://doi.org/10.5005/ip-journals-10024-1773

15. Öztürk BA, Ateş AA, Fişekçioğlu E. Cone-beam computed tomographic analysis of shaping ability of XP-endo shaper and ProTaper next in large root canals. J Endod. 2020;46(3):437-43.

https://doi.org/10.1016/j.joen.2019.11.014

16. Dhingra A, Ruhal N, Miglani A. Evaluation of single file systems Reciproc, Oneshape, and WaveOne using cone beam computed tomography-an in vitro study. Journal of clinical and diagnostic research: J Clin Diagn Res. 2015;9(4):ZC30.

https://doi.org/10.7860/JCDR/2015/12112.5803

17. Elnaghy AM, Elsaka SE, Mandorah AO. In vitro comparison of cyclic fatigue resistance of TruNatomy in single and double curvature canals compared with different nickeltitanium rotary instruments. BMC Oral Health. 2020;20(1):38. https://doi.org/10.1186/s12903-0201027-7

How to cite this article: Panithini DB, Sita Rama Kumar M, Sajjan GS, Madhu Varma K, Kalyan Satish R, Manishaa B. Comparative evaluation of remaining dentin thickness with three different rotary $\mathrm{Ni}$-Ti File systems: an in vitro CBCT study. Int J Dent Mater. 2022; 4(1): 6-10.

DoI: http://dx.doi.org/10.37983/IJDM.2022.4102 